\title{
Keeping in Touch: Tablets Use by Older Adults
}

\author{
Dalit Levy, Elena Simonovsky \\ Zefat Academic College, Kibbutzim College of Education \\ Israel
}

\begin{abstract}
This article is based on a qualitative research conducted during 2012-2013, documenting the process of adjustment to tablet computers by males and females aged 65+. The purpose of the study was to characterize the lifestyle of the population commonly called "the Third Age" regarding the use of touch-screen technology. From an analysis of the data accumulated through ethnographic observations in the homes of the participants and through in-depth interviews with them, a multilayered model emerged, including four dimensions relevant to living with a tablet at the third age: Activity, Learning, Independence, and Barriers. This led to proposing a new model of aging which combines extensive use of devices with integrated touch-screen technology, referred to as "Aging Model 2.0". The research suggests that the use of advanced technology may contribute to a new representation of older adults in society, which, in turn, may lead us to reevaluate our relationship with our parents and grandparents.
\end{abstract}

\section{Introduction}

The world of technology, communications, society, culture, and education is undergoing extensive transformations that deeply influence all of us. At the same time, we are witnessing a remarkable increase in longevity that has led to an aging population [1]. This paper deals with the confluence of these two important sociocultural trends, focusing on the impact that innovative technology might have on older adults, hereby referred to as "the Third Age". Several other terms are widely used to describe this population: seniors, elderly, and golden agers. The terminology sometimes comes with the stigma of social isolation, disease, physical weakness and personal and economic dependence [2]. These barriers could be lowered with the evolution of modern technology as a tool to assist, support, maintain, rehabilitate and improve the quality of life for people who are undergoing changes related to aging. Moreover, the integration of innovative technology into the lives of members of the third age population and their families might also alter perceptions held by younger populations. With this in mind, our study aimed to document third agers who were integrating touch screen technologies into their daily lives and to examine the nature of this new sort of technology-enhanced lifestyle. As a result, a new model of aging in the information age has emerged, termed "Aging Model 2.0", to reflect the variety of web 2.0 tools [3] that our research participants have been using.

The paper begins by setting the theoretical background for the two trends converging in the case of third agers use of advanced technologies, followed by methodological considerations. The key findings are presented next, focusing on the main categories found in our qualitative data, and on the emergent Aging Model 2.0 and its implications.

\section{Theoretical background}

Two important sociocultural trends meet at the intersection of this study, namely the gradual increase in number of the older population around the globe, and the digital revolution affecting every aspect of our lives. Regarding the first trend, Section 2.1 lists some models of aging presented in the field of gerontology. Regarding the second trend, Section 2.2 discusses the digital revolution through lens of the concepts 'Web 2.0' and 'World 2.0'. Section 2.3 ties both trends by discussing the field of gerontechnology.

\subsection{Current aging models}

The Third Age population is very heterogenic and characterized by changes that impact on everyday functions in varying degrees [4]. The literature makes a distinction between normal aging and pathological aging. In addition, different aging models are described, distinct from one another mainly in the way they define the basic concepts and by using different research paradigms. However, a common feature in these models suggests that individuals from the Third Age group can break the boundaries, despite all of the stigmas regarding aging. One of the models suggested in the literature is referred to as "Successful Aging" [5]; Nimrod \& Kleiber [6] propose a theory combining innovation with successful aging; other models refer to "Creative Aging", "Active Aging", and "Productive Aging". The concept of "Positive Aging" [7] combines all of these models and theories and presents us with a strategic policy for achieving the 
optimal conditions for the Third Age population, to encourage their positive involvement in social and economic life, as described in Figure 1.

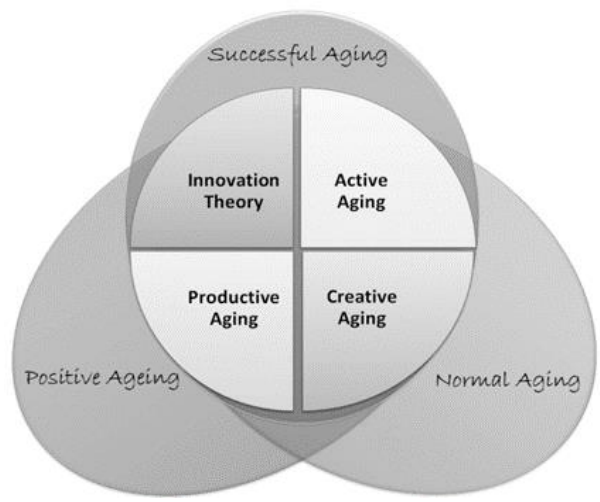

Figure 1. Aging models

The global process of aging is occurring concurrently with huge advances in technology, commonly referred to as a digital revolution effecting every aspect of our lives, including the growing population of the third age. The next sections discusses these impacts.

\subsection{The Internet and the digital revolution}

Technology nowadays is more and more perceived as a tool for empowering citizens. Applications, such as Twitter, Facebook, YouTube, and instant messaging allows user communities to find answers, conduct research, communicate, share and create ideas. This situation presents society with challenges which are dealt with throughout the world using national plans for digital citizenship which include digital literacy and ethics; growing accessibility; educating for digital consumerism, digital law and order, and digital health; and cybersecurity and protection of users' privacy [8]. Such empowerment-by-digital-technology plans are thought to impact all the parts of the society, including the elderly, and to assist in closing digital gaps. The section discusses these impacts through the lens of two terms: Web 2.0 [3] and World 2.0 [9].

2.2.1. Web 2.0. The rise of the Internet is one of the driving forces for this digital revolution. The World Wide Web, initially created as a method for computers to communicate between themselves, has evolved during the first decade of the $21^{\text {st }}$ century as a tool of communication between individuals using Web 2.0, for creating and sharing content. "Web 2.0 is a set of economic, social, and technology trends that collectively form the basis for the next generation of the Internet - a more mature, distinctive medium characterized by user participation, openness, and network effects." [10].
The term "Web 2.0" describes applications with simple user interfaces, which receive data from a number of sources including the users themselves, while maintaining continuous automatic updating, updated by numerous users or simultaneously with them. The process creates a communal web, which provides a dynamic and richer user-experience that allows for both consumption and production of content, for creating interactive programs and applications, and for sharing. These tools are accessible on line and using them does not require installation on a personal computer.

Web 2.0 involves not only new cutting-edge technology, but also a new digital culture, which transcends the closed and conservative ways of social actions and interactions. This change was brought about by billions of people around the world with access to the Internet, and is reflected in terms such as social media and new media. The actions and reactions of Web 2.0 users are often characterized as agile, interactive, creative, and willing to share [10].

During the years since the term Web 2.0 was proposed in 2006, the main principles for designing and programming Internet webpages have been continuously adjusted to the sociocultural trends such as agility, dynamicity, openness, and collaboration. At the same time, while the mobile revolution has joined forces with the Internet revolution, numerous types of Web 2.0 applications have been flooding the cyberspace. Among these are social networks like Facebook and Twitter where users share information and knowledge about everything, including issues of health and illness and plenty of other issues that are relevant for the Third age. For example, Twitter hosts a wide range of information and updates regarding common $65+$ health issues and diseases, such as Alzheimer's and dementia. There is also sharing of tweets by experts through Twitter. Professional medical experts, health groups, and commercial companies use such newmedia channels in order to trade information on medical and pharmaceutical research, Alzheimer and dementia risk factors, and ways to reduce risks [11].

2.2.2. World 2.0 - a digital ecological system. The complex two-way relationship between mobile devices, computers, and humans has received a significant impetus in light of the Web 2.0, which foresaw the change in the relationship between Internet users and Internet content, as well as the change in the relationship among users themselves.

The potential embodied in this is already affecting society. Flexible working-time from in or out of the office requires the various organizations to be flexible through their connection to the Internet. Online purchases provide more than the item purchased, but also membership in the shoppers' community. The online gaming phenomenon is expanding throughout the world. Cloud technologies 
allow for easy and immediate access to information and communication from everywhere and through any mobile device. Collaboration and active participation with family and friends, colleagues and clients is possible from anywhere in the world any time. Web 2.0 tools provide the technological basis for all these as well as for a variety of digital citizenship projects which serve the purposes of reducing the digital gap.

On the down side of World 2.0, the book "Alone, Together", discusses the increasing dependence of the people and the society on these advanced Web 2.0 technologies, tools, and applications [12]. The author, Sherry Turkle, claims that the digital revolution changes not only our behavior - it also influences our very essence and create a new type of personality. As the title of her book hints, Web 2.0 technologies are not truly connecting us to others we are not together in the "old" sense of the word. Accordingly, we are more alone, when humanity shuts itself off from the world through communicating with the world.

As a result of the discussion revolving around the cultural changes in the digital age, the idea of life in the "World 2.0" space was introduced in 2009 [9]. World 2.0 is a digital ecological system: a hyperlinked space with its various parts, globally complex and full of human-computer interactions, non-human interactions and inter-human interactions.

A variety of tablet computers, along with smartphones, are the main method of assimilating the Web 2.0 applications in World 2.0. Structurally, the tablet computer is a screen, which reacts to the touch of a finger. Below the surface is a computer, which usually includes a processor, hard drive, memory, and wireless network connections. Although many believe that the first tablet computer was the iPad, introduced by Apple in 2010, the history of touchscreen devices goes back to the 1960s. Due to space limitations, this fascinating history cannot be detailed here. However, it is worth noting that the technological development of tablet computers with touch screens has both introduced a new computing paradigm and enabled the spreading of World 2.0. The devices in this new paradigm are small, personal, lightweight and affordable, connected by wireless and equipped with a range of simple multimedia and modular software for data-search, learning and games. As reflected by Steve Jobes' vision from 2005, the tablet computer comes with a touch screen and without an integrated keyboard or unnecessary buttons. Indeed, the iPad declared by Jobes in 2010 marked the rise of this new paradigm, sometimes referred to as the "post-PC age".

The tablets, built on touch-screen technology, are thought of as an answer to the problems of thirdagers who are challenged by traditional computers. A touch-screen user is within touching distance of the potential services and treasures of the Internet, while accessibility of the interface symbols and icons lessens the frustration of the adult user. Research shows a proven psychomotor advantage of tablet computers versus the ordinary mouse and keyboard [13]. The touch-screen reduces by $35 \%$ the time that the adult invests in movement on the screen compared with the mouse. There is also a decrease in the number of errors with an accompanying increase in efficiency. Although the advantages remains, it should be noted that touch-screen devices require motoric skills, which are difficult for people who suffer from arthritis, tremors and other problems [14].

To summarize this section, living in World 2.0 involves touch interfaces that are being employed everywhere. In ticket-vending machines for public transport, shows and the arts; in queue-number machines for clinics, banks and post offices; in information screens of interactive boards and electronic guides in many public places; and of course, for personal communication and multimedia: smart mobile phones, hand-held computers and various tablets. Elderly people living in the same world experience the nature of World 2.0 and participate in the interactions influenced by the digital revolution through extensive use of Web 2.0 tools in these tablet computers. Thus, the worlds of technology and real life interact in the digital ecological system of World 2.0 - a global, complex space that is full of human computer interactions, artificial interactions and interpersonal interactions. The Third Age population group is an integral part of this hyperlinked system, hence the importance of dealing with the impact of World 2.0 on them.

\subsection{Assistive technologies and gerontology}

Technology that used to be available in the past only to a selected few has now become much more accessible, more efficient and faster and used by many for a variety of purposes. Technologies that were initially developed for military uses are making their way into our civilian life and into everyday applications, similar to the Internet, which initially served the professional science community, and then made its way into everyone's daily routine. Technological gadgets which began as amusing toys, have found their way into education, medicine, nursing and rehabilitation, allowing people with various disabilities to be integrated into their natural habitat, while maintaining the highest degree of independence and an acceptable standard of living.

2.3.1. Assistive technologies. The developing sector of technology referred to as "assistive technologies" emphasizes technologies that help users to bypass their disabilities and lead a normal life [15]. In the past, assistive technological tools would assist disabled users with mainly physical and sensory 
disabilities. Today, in parallel to the digital revolution, the field is reaching additional special populations, such as the elderly and persons with cognitive disabilities. Moreover, it has merged with nursing technology and preventing certain medical problems, such as dementia and depression, sociopsychological problems, such as loneliness and dependence on others for everyday functions, and so on. In addition, communication applications of Web 2.0 type and new technologies help create an infrastructure for exchange of medical information, for supporting high risk patient groups, for treatment and prevention of injuries and disease, when elements such as time and distance are crucial for successful professional intervention [16].

Assistive technology not only modifies the home allowing an elderly person an independent life style, but also assists in mobility and tourism. New applications are constantly introduced which allow functioning at a level which was previously impossible, and the $65+$ population is the fastest growing sector of Internet consumers. Creating an interpersonal interaction online opens a new window of opportunity for those people feeling distressed, when medical treatment and counseling is inaccessible due to excessive physical demands or language barriers, and mobility difficulties in emergencies, such as war, terrorist attack or natural disasters. The online connection is much faster and effective in traumatic and post-traumatic times in support groups for chronic diseases, depression and anxiety, than organizing and operating face-to-face groups. Access to general medical information and personal data allows health insurance policyholders to book doctor's appointments, receive test results and medical counseling in their homes, check healthrelated data regardless of time, seek and locate emotional support online [16].

Indeed, various studies indicate a connection between Internet usage and the level of a person's independence, and his or her cognitive and physical performances [8]. However, scientists do not consider the Internet as a "miracle drug" for coping with the changes of aging and studies conducted prior to the introduction of touch screen devices have not found conclusive evidence for the hypothesis which claims that using a computer at an older age is efficacious. Still, it has been suggested that computer-based communication has great potential for supporting people of advanced age [17].

2.3.2 Gerontechnology. Gerontechnology is defined as the utilization of technology to improve the welfare of adults and elderly people using tools available to us everywhere and at any time [18]. The aim of gerontology is to enhance the level of functioning and the quality of life of elderly persons who have experienced changes in their health, with physical and psychological limitations caused by their age. The emphasis is on safety issues for people requiring assistance by maintaining age-friendly environments that allows effective access to everyday services, such as automatic illumination of rooms and hallways at nighttime [15]. In addition to these mechanical accessories, a wide range of sensor-based applications has been developed. These include digital secretaries to remind us of the time for medication; video-conference applications that allow us to remain in constant touch with family members, doctors and patients; and the smart systems that can aid people in taking the right pill, in reading a brochure and providing additional information, converting sound and voice to text for the hearing-impaired or text to sound for the visually-impaired [18]. The relevance of these technologies has also been tested in the field of book reading for people with mobility limitations. In addition, sensor systems set up at elderly homes can collect different vital signs such as weight, blood pressure and other data; create an information database to aid prevention of health risks, such as falling, prevention of future asthma attacks, heart attacks, blood pressure spikes or diabetes by notifying relatives or caretaker, recording sleep, description of sleep quality and the time a person is awake and active. Using such systems allows the patient's physical activity to be monitored, increases the level of safety and creates a friendly living environment. However, these uses might constitute for the elderly population an invasion of privacy.

More and more sectors of the third-age population nowadays interact with various technologies in their day-to-day activities. It is highly desirable therefore that new technologies are adapted for use by all age groups, including those over 65. At the same time, new technology is still mostly inaccessible to those in the elderly population who lack additional income apart from their pensions, and the high cost of new technology usually prevents them from using it, while creating digital and inter-generational differences. Increasing the gap between young and old mostly excludes the latter from modern life, isolates, depresses and maybe even shortens their life span. One of the programs for reducing this gap is the 'Active Aging 2.0' [8] which operates on a Web 2.0 platform. This program promotes a wider use of social media and cooperative digital communication tools by members of the elderly community in order to transform them into active digital citizens in the virtual space of society.

The digital gap is not only a function of poverty and technology costs. Among the contributory causes of technology-exclusion is the low level of graphic design adaptation, for example, low contrasts of text on screens, which affects the interpretation of the text and increases the length of time it takes for elderly people to read the text. Researchers relate 
such design issues to a lack of awareness of the importance of the new technology and its positive effects on the aging process [18]. Technology experts, designers and engineers often neglect the elderly population, thereby increasing the gaps and preventing them from using the technologies. Among the barriers are myths relating to the interaction between a human being and a computer. Those myths are popular among engineers and programmers, and throughout society, even among elderly people themselves [19]. The most obvious myth is that people of the middle generation and certainly people of the young generation will use computers without a problem, once they approach the third age. This myth is accompanied by abstention and a lack of investment in the current elderly population regarding advanced technologies. Other myths are that old people are not interested in using computers, that they are unaware of the capabilities of computers because they perceive them as useless and unnecessary, that they are unable physically to use technology, and that they simply cannot understand the interactivity of computer technology.

The findings of the current study, as further presented in Section 4, bring first evidence against some of these myths in the case of third-agers using new technologies introduced by the first generation of tablets. In that way, our work seek to raise awareness to the importance of interweaving new technologies and gerontology, as well as to the positive effects such use might have on the aging process.

\section{Method}

The use of tablet computers by male and female members of the Third Age population group is a relatively new phenomenon, adding a new dimension to the existing theories regarding aging in the modern era. This phenomenon was examined in this study using an ethnographic approach [20] that allows for a description of human and social situations through the individual subjective perspective of the participants using their own words. The use of qualitative tools for data gathering allows documentation of the natural activities of an elderly person while maintaining her/his authentic voice.

The documentation was carried out between October 2012 and September 2013 by a combination of ethnographic observations and open interviews, a combination which allows cross-reference of data collected from multiple, and independent sources.

The participants were nine males and females ages $65+$ who have been using tablet computers for no more than two years, and one young IPad applications developer. The participants vary in terms of socio-economic level, health status, knowledge and pre-existing experience of this type of technology as well as place of residence.

The data were obtained in the homes or places of employment of the participants. All of the participants received a general explanation regarding the general topic of the study and all of them expressed their agreement to be interviewed, while maintaining their confidentiality. The observations and the interviews were methodically and meticulously documented and transcribed, conducted at various times - weekdays, holidays, at different hours of the day and in different seasons of the year. As is customary in an evolving study, the qualitative analysis phase began simultaneously with the gathering of the data, occasionally affecting the order of data gathering and the composition of the participants.

\section{Key findings}

Overall, the participants in this study found use of the touch screen devices easy and intuitive, and used them for a variety of purposes that led to, among other things, the creation of personal, family, social and professional activities. In what follows, three main results are presented, answering three research questions: (1) How and for what purposes do thirdagers use their tablets?; (2) What are the advantages and disadvantages of using tablets, as seen and expressed by the participants?; And (3) What changes to the current aging models are introduced through the use of tablets by third-agers?

\subsection{Variety of Uses}

As has been written above, the third agers used their tablets for a variety of personal, family, and social activities: in one case, the interviewee even regarded the tablet as a family member. They also used them for keeping up-to-date and learning for professional needs, and found that they contributed to their independence in decision-making and control of information and time-organization. In some cases, using the tablet was described as a way for mediating and reducing social gaps.

During the first analytic step, five categories of uses emerged from the inductive analysis of the data gathered from the participants: (a) uses related to active lifestyle, (b) uses related to being a technophile, (c) uses related to digital citizenship, (d) uses related to independent learning, and (e) uses related to the participants' relationships with their younger family members. Table 1 details these various uses. 
Table 1. Uses of tablets by older adults

\begin{tabular}{|c|c|}
\hline $\begin{array}{l}\text { Emergent } \\
\text { category }\end{array}$ & Specific use \\
\hline \multirow{10}{*}{ 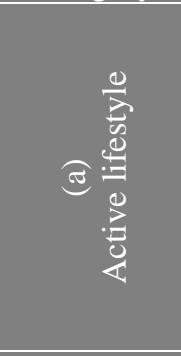 } & Sport activities \\
\hline & Shopping \\
\hline & Work duties \\
\hline & Individual interests \\
\hline & Reading \\
\hline & Driving \\
\hline & Excursions, trips \\
\hline & Crafts \\
\hline & Photo taking \\
\hline & Music \\
\hline $\begin{array}{l}\text { Emergent } \\
\text { category }\end{array}$ & Specific use \\
\hline \multirow{2}{*}{ อ } & $\begin{array}{l}\text { Advanced uses based on a rich technological } \\
\text { biography }\end{array}$ \\
\hline & Combining the use of PCs and Tablets \\
\hline \multirow{6}{*}{ 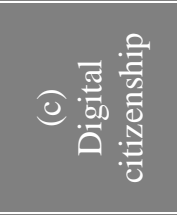 } & Digital Literacy \\
\hline & Digital Ethics \\
\hline & Digital communications \\
\hline & Accessibility \\
\hline & E-commerce and digital consumption \\
\hline & Digital Health \\
\hline \multirow{9}{*}{ 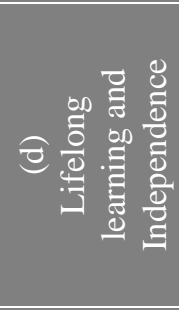 } & Empowerment \\
\hline & Respect \\
\hline & Pleasure \\
\hline & Creativity \\
\hline & Need for recognition \\
\hline & Decision making \\
\hline & Control \\
\hline & Autonomy \\
\hline & Professional and self- development \\
\hline \multirow{4}{*}{ 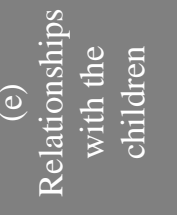 } & Alerts \\
\hline & Reversal of roles in the family \\
\hline & Need for continuous keeping-in-touch \\
\hline & Advice in purchasing the tablet \\
\hline
\end{tabular}

Table 2. Difficulties and Barriers

Time constrains
Software complications
Issues of saving and locating saved files
Difficulties with attention distribution
between input/output devices

The inductive analysis of the participants' discourse regarding their use of touch screen devices also raised a range of difficulties and barriers that exist between the elderly population and the innovations of technology [12]. Table 2 contains two categories in this regard: difficulties that were described by the participants, and issues related to age losses that were expressed by them.

\subsection{Advantages and Disadvantages}

Following the range of the uses as well as of the difficulties found in the first analytic step, the analysis continued seeking for advantages and disadvantages of "keeping in touch", namely using touch-screen technologies, as these were expressed by our third age participants.

As expected, our interviewees noted the price as a disadvantage, as well as the need for wi-fi installation at home. They also mentioned short battery life, insufficient memory and one-way camera as disadvantages. Ergonomically, they noted both issues of sharpness and clarity of graphics and text in some applications [19] and issues of placing the tablet when they wanted or were forced (for health reasons) to use it in bed. Another issue raised by our third-agers was the continuous need for advice and support. Figure 2 shows the main four disadvantages through the eyes of the participants.

As a possible solution to some of these disadvantages, guidelines are suggested [21] for three aspects of website design to accommodate the elderly population: (1) legible text design, (2) increase in memory, (3) easier navigation and accessibility to internet content. Although articulated in the pre-tablets era, applying these guidelines into tablets and applications design is supposed to result in more accessible websites and more access to online information for members of the elderly community, as well as increasing their enthusiasm towards technology. Recently, this point of view has been receiving growing public attention in defining a common cause to bridge the digital divide in this community.

Figure 2 also presents the four main advantages that the interviewees mentioned: immediate use; ease of learning the variety of apps; connectivity; and interactivity. Being placed on a scale, Figure 2 shows that in our participants' eyes, the advantages edge weighs more than the disadvantages edge. In other words, they see the tablet as a blessing in spite of the disadvantages, the difficulties, and the barriers. 


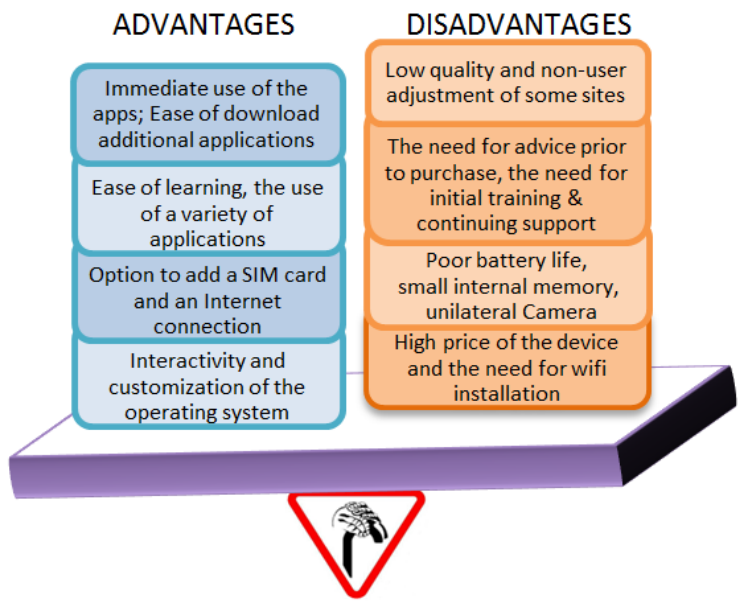

Figure 2. Tablets pros and cons through the participants' eyes

The way that third-age population see the advantages and the disadvantages of using tablets at their age might guide tablets designers, application programmers, supporters and helpers in creating more accessible and assistive technologies and services directed at this growing population.

\subsection{Towards a New Aging Model}

In the last analytic step, the wide array of emergent categories as described in Sections 4.1, 4.2 above was further re-arranged in four dimensions: (1) Activity; (2) Learning; (3) Independence; and (4) Barriers. The final categorical system is detailed in Table 3.

One example, included in the third dimension of Independence, is expressed via the title of a previous account of this study [22]: "Meet Vasia, our new family member". The words of this title appear in an an interview with one of the female participants, who told us about her husband's human attitude towards his tablet, including naming it with a traditional Russian name. She added: "I was mad at him at first. We said, wait until he stops playing with it, until he has had enough, but he didn't stop, and we had to enlarge the family to include Vasia. We now welcome it, knowing for sure that my husband is more with Vasia than with us" (interview on June 14, 2013). We categorized this episode as family, social and professional communication (appears first in the third dimension).

Another example categorized under the same dimension of Independence is the fear of being dependent on younger family members. Shai told us in his interview about how he succeeded in directing both his children into the computing profession, and proudly described his daughter's career in an international information security company as well as his son's senior job in a major telecommunication firm. He added: "I was once their advisor, now I use their advice. The roles in our family have been reversed. I just don't want it to become complete dependence" (interview on July 31, 2013).

Table 3. The final categorical system
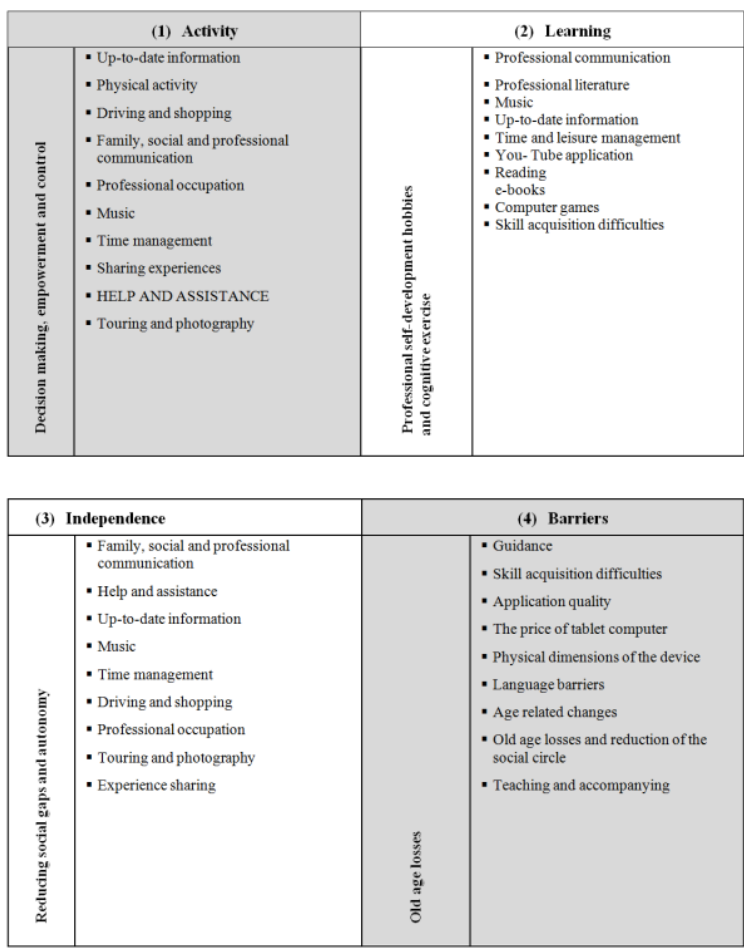

An interesting example from the first dimension Activity - is taken from an interview with Willy, the husband who named his tablet Vasia. Willy is a retired medical doctor who still works in his profession. He connects computers and tablets directly to his ability to continue working at his age: "I always need to be updated with all the news in my professional field. The computer is the ideal tool for that. As it turned out, I use my computer and tablet at least two hours a day. I read articles and medical news" (interview on June 14, 2013).

The Activity dimension was widely mentioned by our participants not only with regard to professional needs, as in the aforementioned example, but also in a variety of other categories such as physical activity: running, walking, dancing, swimming, etc.; cognitive activity: reading, games, crosswords, etc.; social activity; touring and tourism; and new-media activity. Moreover, some participants described technology using specific verbs and expressions hinting at an active and dynamic perception, as is shown in the bulleted excerpts, where the verbs of activity are capitalized.

- "you can't GO with technology, you can only GO after it" (Dan, February 19, 2013)

- "...the technology RUNS ...you don't even need to get out of bed - you touch, and you FLY ..." (Dan $-2^{\text {nd }}$ interview, July 1,2013$)$ 
- "...now (with the tablet) I have no problem waiting - I am PLAYING. I have something to DO" (Rina, May 30, 2013)

- "In my age it is harder to RUN with technology..." (Sami, May 31, 2013)

- "You can't make it with the RATE of technology change" (Shai, July 31, 2013)

These examples above draw a partial picture of the phenomena investigated, and the citations only briefly exemplify the rich data obtained through a vast description of the participants' use of tablets and their accompanying discourse. Even though, contrary to the persistent stereotype concerning conservatism among the elderly population, the inductive analysis shows active people who are open to technological change, despite the difficulty stated by some, mainly regarding the operation of regular computers.

It is apparent in all the four dimensions of the final categorical system, as well as in most of the categories that are included in each dimension, that the use of tablets by the third-age population changes various aspects of their daily lives. We therefore suggest that the existing aging models, as these have been presented in the literature and summarized in section 2.1 above, might also exhibit some transformation in the wake of World 2.0 [9]. Our proposal is further detailed in the next section.

\section{Proposed Aging Model 2.0}

The findings of this study describe people who are active, open to technological changes, and who incorporate the tablets into everyday life, enabling ease of searching for and reading information, promoting social, family and professional communication and assisting in time management and leisure. The data also introduce compensation for old-age losses [4], reduction of social gaps, higher mobility and social involvement and ultimately happiness. These findings shatter the prejudices regarding old age and aging as a limitation $[1,19]$.

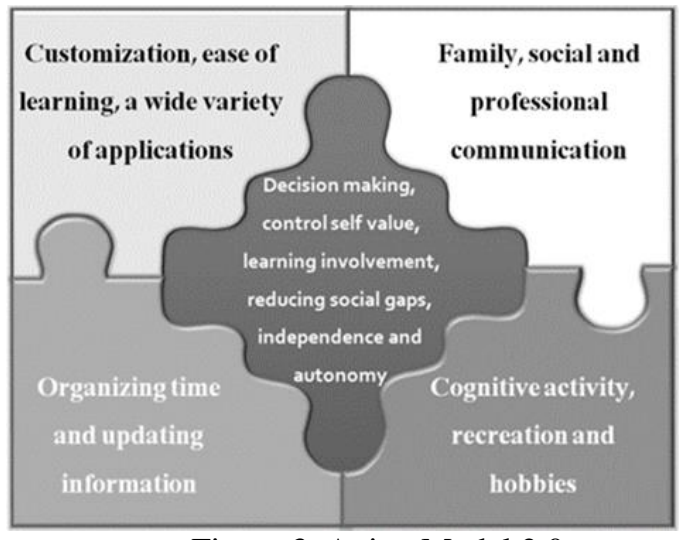

Figure 3. Aging Model 2.0
As a result of the significant readings observed during the analysis phase, we developed a model which we chose to name "Aging 2.0" (see Figure 3), to echo the varied "Web 2.0" tools which the participants used and to echo the online world in which we - and they - live. Aging Model 2.0 represents how the integration of advanced technologies at the Third Age may improve the daily function of that population.

\section{Concluding Remarks}

From an analysis of the data accumulated through ethnographic observations and through in-depth interviews with the participants, emerged a structure, Aging Model 2.0, as a conjunction of the aspects relevant to living with a tablet at the third age as these appear in Table 3 and Figure 3.

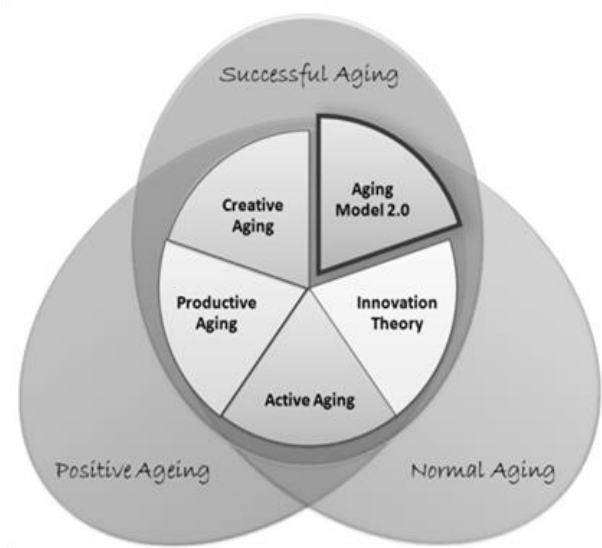

Figure 4. Aging Model 2.0 as the fifth element in the array of existing models

Figure 4 further integrates this emergent model into the preexisting aging models detailed in Section 2.1. This integration could contribute to a new and different representation of the Third Age population in society, to encourage us all to re-evaluate our relationship with our parents and grandparents, and allow the members of the Third Age population group to re-evaluate their abilities regarding modern technologies that are relevant to our coexisting lives.

It is our sincere hope that this study and the proposed model will contribute to raising social awareness of this issue and to a change in popular pre-existing misconceptions and prejudice in the public, and at the same time enable Third Agers and those who support them to successfully integrate and utilize touch screen technology into their everyday life.

\section{References}

[1] Charness, N., and Boot, W. R., (2009). 'Aging and Information Technology Use: Potential and Barriers', Current Directions in Psychological Science 18(5), pp. 253-258. 
[2] Kaplan, A., (2013). Preface to Paradise, Life in the Current Site of Old Age, Series for Sociology and Anthropology, Rasling: Tel Aviv (In Hebrew).

[3] O'Reilly, T., (2007). 'What is Web 2.0: Design Patterns and Business Models for the Next Generation of Software', Communications \& Strategies, 1(17).

[4] Baltes, P. B., (1997). 'On the incomplete architecture of human ontogeny. Selection, optimization, and compensation as foundation of developmental theory', The American psychologist, 52(4), pp. 366-380.

[5] Rowe, J. W., and Kahn, R. L., (1999). 'Successful Aging', in K. Dychtwald (ed.) Healthy Aging: Challenges and Solutions, Gaithersburg, Maryland: Aspen, pp. 27-44.

[6] Nimrod, G., and Kleiber, D., (2007). 'Reconsidering Change and Continuity in Later Life: Toward an Innovation Theory of Successful Aging', The International Journal of Aging and Human Development, 65(1), pp. 122.

[7] Rudman, D. L., (2006). 'Positive aging and its implications for occupational possibilities in later life', Canadian Journal of Occupational Therapy, 73(3), pp. 188192.

[8] Consoli, D., (2012). 'A model of Active Aging 2.0 to stimulate older adults in the use of virtual social networks', Intergenerational Solidarity and Older Adults' Education in Community, 296.

[9] Karakas, F., (2009). 'Welcome to World 2.0: the new digital ecosystem', Journal of Business Strategy, 30(4), pp. 23-30.

[10] O'Reilly, T., \& Musser, J., (2006). 'Excerpts of Web 2.0 Principles and Best Practices.', O'Reilly Media; http://oreilly.com/catalog/web2report/chapter/web20_repor t_excerpt.pdf (2 December 2013).

[11] Robillard, J. M., Johnson, T. W., Hennessey, C., Beattie, B. L., Illes, J., (2013). 'Aging 2.0: Health Information about Dementia on Twitter', PLoS ONE, 8(7).

[12] Turkle, S., (2011). Alone together: Why we expect more from technology and less from each other. Basic Books, New York.

[13] Findlater, L., Froehlich, J. E., Fattal, K., Wobbrock, J. O., Dastyar, T., (2013). 'Age-related differences in performance with touchscreens compared to traditional mouse input', Proceedings of the SIGCHI Conference on Human Factors in Computing Systems (pp. 343-346); www.cs.umd.edu/ jonf/publications/Findlater_AgeRelated DifferencesInPerformanceWithTouchscreensComparedTo TraditionalMouseInput_CHI2013.pdf (19 November, 2013).

[14] Caprani, N., O’Connor, N. E., Gurrin, C., (2012). 'Touch screens for the older user'. A. F. Cheein, (ed.). Assistive Technologies. pp. 95-118. http://cdn.intechopen.com/pdfs/31905/InTech-Touch screens_for_the_older_user.pdf (19 November, 2012)
[15] Piattini, M. (2012) 'The role of ICTs in ageing'. LYCHNOS 8, pp. 60-64.http://www.fgcsic.es/lychnos/ upload/publicacion.14.ficPDF_ingles.LYCHNOS_8_ING_ web.pdf (23 August, 2012)

[16] Hall, A. K., Stellefson, M., Bernhardt, J. M., (2012). 'Healthy Aging 2.0: the potential of new media and technology', Preventing Chronic Disease, 9.

[17] Dickinson, A., Gregor, P., (2006). 'Computer use has no demonstrated impact on the well-being of older adults'. International Journal of Human-Computer Studies, 64(8), 744-753. doi:10.1016/j.ijhcs.2006.03.001.

[18] Cohen-Mansfield, J., Biddison, J., (2007). 'The Scope and Future Trends of Gerontechnology: Consumers' Opinions and Literature Survey'. Journal of Technology in Human Services 25(3), 1-19. doi:10.1300/J017v25n03_01

[19] Wandke, H., Sengpiel, M., Sönksen, M., (2012) 'Myths About Older People's Use of Information and Communication Technology', Gerontology, 58(6), pp. 564-570.

[20] Guba, E.G., Lincoln, Y.S., (1989). Fourth Generation Evaluation, London, UK: Sage Publications.

[21] Hart, T., Chaparro, B., \& Halcomb, C., (2008). 'Evaluating websites for older adults: Adherence to seniorfriendly guidelines and end-user performance'. Behaviour \& Information Technology, 27(3), 191-199. psychology.wichita.edu/surl/usabilitynews/61/older_adults .htm (30 August, 2013)

[22] Levy, D., Simonovsky, E., (2015). '"Meet Vasia, our New Family Member": Tablets use by Older Adults'. In C. A. Shoniregun \& G. Akmayeva (Eds) Proceedings of the World Congress on Education (WCE-2015), 132-136. 